\title{
Lutowanie dyfuzyjne tytanu z użyciem przekładek z miedzi i niklu
}

\author{
Diffusion brazing of titanium with copper \\ and nickel as a filler metals
}

\section{Streszczenie}

W artykule omówiono problematykę lutowności tytanu. Opisano zasadę procesu i mechanizmy powstawania połączeń wykonanych poprzez lutowanie dyfuzyjne. Przestawiono wyniki badań metalograficznych i wytrzymałościowych połączeń tytanu technicznego (grade 2) lutowanego dyfuzyjnie $z$ użyciem przekładek z miedzi (CF032A) i niklu (Ni 99,0) oraz podano parametry lutowania dyfuzyjnego. Badania metalograficzne przeprowadzono przy zastosowaniu mikroskopii świetlnej. Podano wyniki statycznej próby ścinania uzyskanych połączeń lutowanych.

\section{Abstract}

The brazeability problem of titanium and its alloys have been discussed in the paper. The principles of the diffusion brazing process and application conditions have been presented. The structures and mechanical properties of the joints of titanium (grade 2) diffusion brazed with the use of sandwich type copper (grade CF032A) and nickel $(\mathrm{Ni} 99,0)$ as a interlayers as well as brazing conditions have been given. The structural tests were conduced using light microscopy. The results of shear strength tests of obtained joints were also presented.

\section{Wstęp}

Tytan jako metal silnie reaktywny należy do materiałów trudno lutowalnych $[3 \div 6]$. Jedną $z$ najkorzystniejszych technicznie metod łączenia go jest lutowanie dyfuzyjne. Ta metoda, łącząca cechy zgrzewania dyfuzyjnego i lutowania, jest definiowana najczęściej jako: „proces lutowania, w którym mechanizm tworzenia się lutowiny oparty jest przede wszystkim na zjawisku dyfuzji pomiędzy materiałami łączonymi i lutem” lub też jako: „proces lutowania, w którym zjawisko dyfuzji decyduje o składzie chemicznym i właściwościach fizycznych lutowiny, uzyskanej ze stopienia dodanego lutu lub lutu powstałego

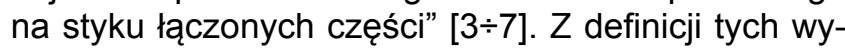
nika podział procesu lutowania dyfuzyjnego na dwa rodzaje. W pierwszym wykorzystuje się spoiwo dodawane $z$ zewnątrz, a ciekły lut powstaje $w$ wyniku

Dr hab. inż. Zbigniew Mirski, prof. PWr - Politechnika Wrocławska, dr inż. Maciej Różański, dr inż. Andrzej Winiowski - Instytut Spawalnictwa w Gliwicach.

wzajemnej dyfuzji składników spoiwa i materiału podstawowego. Drugi rodzaj to lutowanie bez spoiwa dozowanego z zewnątrz. Ciekły lut tworzący lutowinę powstaje wówczas na styku łączonych materiałów w wyniku wzajemnej dyfuzji ich odpowiednich składników. Zjawisko takie dotyczy tylko układów materiałowych, których składniki (lub one same) tworzą fazowe układy równowagi $z$ mieszaniną eutektyczną lub $z$ ciągłym roztworem stałym z minimum na linii likwidusu. Wtedy stop o składzie eutektycznym lub o składzie roztworu stałego $z$ minimum stanowi spoiwo w procesie lutowania $[3 \div 7]$.

W zależności od mechanizmu powstawania oraz budowy strukturalnej uzyskanego połączenia lutowanego, lutowanie dyfuzyjne dzieli się na lutowanie nisko- i wysokotemperaturowe. $\mathrm{W}$ pierwszym przypadku w wyniku dyfuzji składników lutu i materiału łączonego powstają fazy międzymetaliczne o temperaturze topnienia wyższej od temperatury, w której odbywa się proces lutowania. $W$ drugim przypadku proces prowadzony jest w taki sposób, aby w złączu nie były obecne fazy międzymetaliczne, a obszar złącza stanowił roztwór stały $[7,11]$.

$Z$ analizy dostępnej literatury naukowo-technicznej oraz układów równowagi fazowej tytanu $z$ innymi 

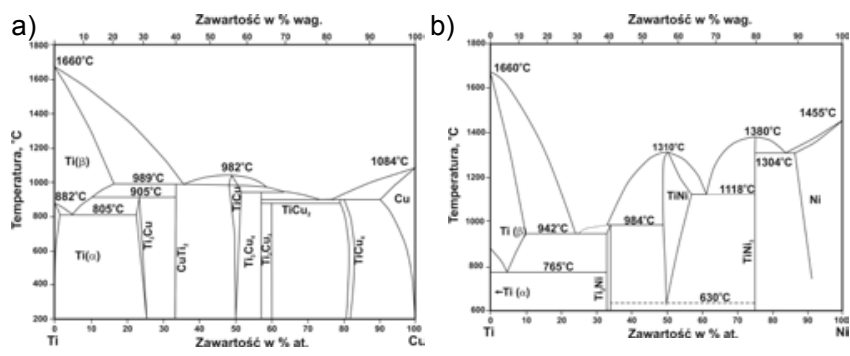

Rys. 1. Układy równowagi: a) Ti-Cu, b) Ti-Ni [12]

Fig. 1. Equilibrium phase diagram: a) Ti-Cu b) Ti-Ni [12]

metalami wynika, że metal ten z większościa metali technicznych tworzy skomplikowane układy z licznymi fazami międzymetalicznymi o niższej lub zdecydowanie niższej temperaturze tworzenia tych faz niż temperatura topnienia tych metali $[1,2,5,12]$. Analizując układ równowagi fazowej Ti-Cu (rys. 1a) oraz Ti-Ni (rys. 1b) można zauważyć, że zastosowanie czystej miedzi lub czystego niklu jako przekładki lutowniczej umożliwi lutowanie dyfuzyjne.

Przedstawiono wyniki badań lutowania dyfuzyjnego tytanu przy użyciu miedzi i niklu. Celemtych badań było zbadanie możliwości zastosowania czystych metali jako spoiw do lutowania dyfuzyjnego tytanu oraz określenie wpływu materiałowo-technologicznych warunków lutowania dyfuzyjnego na strukturę i właściwości mechaniczne uzyskanych połączeń.

\section{Materiały podstawowe i dodatkowe do badań}

Do badań zastosowano tytan w postaci blachy o grubości 25 mm grade 2 wg ASTM B 26579 (maksymalne ilości zanieczyszczeń w \% wag.: 0,1\% C, 0,25\% O, 0,03\% N, 0,0125\% H, 0,03\% Fe), z której metodą obróbki skrawaniem wykonano próbki walcowe o średnicy 20 i długości $15 \mathrm{~mm}$.

Jako przekładki w procesie lutowania dyfuzyjnego zastosowano: miedź CF032A wg PN-EN 1412 i nikiel Ni 99,0 wg PN-ISO 9722.

Miedź i nikiel, użyte jako materiały dodatkowe, tworzą z tytanem niskotopliwe mieszaniny eutektyczne o składach wagowych wg oznaczeń: Cu72Ti28, $\mathrm{Ni28,5Ti71,5}$ i temperaturze przemiany odpowiednio: 875 i $942^{\circ} \mathrm{C}[8,11,12]$.

\section{Wykonanie połączeń próbnych}

Do badań metalograficznych oraz statycznej próby ścinania połączeń lutowanych tytanu grade 2 zastosowano próbki walcowe. Elementy próbek lutowanych doczołowo ułożono swobodnie współosiowo w pozycji pionowej. Ten typ próbki (próbka walcowa) i odpowiednie oprzyrządowanie umożliwiają przeprowadzenie czystego ścinania połączenia lutowanego podczas prób wytrzymałościowych.
W celu zwiększenia powierzchni przylegania i drogi dyfuzji składników materiału podstawowego i lutu, przed procesem lutowania powierzchnie elementów szlifowano na papierach ściernych o końcowej numeracji 800 . Bezpośrednio przed lutowaniem próbki trawiono w roztworze kwasu fluorowodorowego i azotowego. Dopasowane kształtem do złącza przekładki z folii miedzianej i niklowej bezpośrednio przed lutowaniem odtłuszczano w acetonie i umieszczano po dwie (łączna grubość 0,1 mm) pomiędzy łączonymi elementami.

Wszystkie próbki lutowano w piecu próżniowym S 16 firmy TORVAC w próżni w zakresie $10^{-4} \div 10^{-5} \mathrm{mbar}$.

Temperaturę i czas lutowania ustalono, opierając się na dostępnych informacjach literaturowych oraz analizie oddziaływania fazowego tytanu z miedzią i ni-

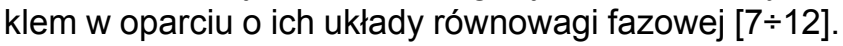

Lutowanie tytanu grade 2, przy zastosowaniu miedzi jako przekładki lutowniczej, przeprowadzono w temperaturze: 950,1000 oraz $1030^{\circ} \mathrm{C}$ i czasie lutowania w każdej temperaturze: 1, 10, 20, 30 i 40 min. Przy zastosowaniu niklowej przekładki już w pierwszej próbie lutowania (1 min) uzyskano niską jakość połączeń (brak wypełnienia szczeliny lutowniczej, brak zwilżenia powierzchni bocznej próbek). Z tego względu dalsze próby lutowania z zastosowaniem niklu ograniczono dla czasów lutowania 1 i 30 min, a ze względu na uwrażliwienie tytanu technicznego na silny rozrost ziaren w zakresie występowania fazy $\beta$ korzystne jest, aby czas wytrzymania w temperaturze lutowania był możliwie krótki. Ważne jest też aby podczas lutowania tytanu technicznego zaszła przemiana fazowa $\alpha \leftrightarrows \beta$, gdyż w tytanie $\beta$ współczynniki dyfuzji atomów metali są o kilka rzędów wielkości większe niż w tytanie $\alpha$.

W każdym przypadku nagrzewanie próbek do temperatury lutowania prowadzono z wytrzymaniem izotermicznym w temperaturze $700^{\circ} \mathrm{C}$ w czasie 20 min w celu desorpcji gazów z powierzchni elementów lutowanych.

Oceniając wizualnie jakość połączeń tytanowych stwierdzono dobrą jakość w przypadku połączeń wykonanych w temperaturze 950,1000 i $1030^{\circ} \mathrm{C}$ i we wszystkich stosowanych czasach lutowania przy użyciu miedzi. W przypadku połączeń wykonanych przy użyciu niklu nie uzyskano połączenia o fizycznej ciągłości podczas lutowania w temperaturze $950^{\circ} \mathrm{C}$ i czasie $1 \mathrm{~min}$. Próbki lutowane w czasie $1 \mathrm{~min}$ i temperaturze 1000 oraz $1030^{\circ} \mathrm{C}$ wykazywały fizyczną ciągłość, natomiast nie stwierdzono całkowitego wypełnienia szczeliny lutowniczej ciekłym lutem i zwilżenia powierzchni bocznych próbek. Natomiast próbki lutowane w czasie 30 min wykazywały dobrą jakość dla wszystkich trzech temperatur wartości lutowania.

\section{Struktury połączeń lutowanych tytanu grade 2}

Próbki do badań metalograficznych mikroskopowych przygotowano przez ich szlifowanie na papierach 
ściernych: $80,320,1000$ i 2500 , a następnie polerowanie na płótnach polerskich $z$ dodatkiem zawiesiny polerskiej kolejno - diamentowej i korundowej o wielkości ziarna odpowiednio 3 i 0,05 $\mu \mathrm{m}$.

Badaniom metalograficznym poddano wszystkie złącza, wykonane $\mathrm{w}$ temperaturze lutowania $1000^{\circ} \mathrm{C}$ i wszystkich stosowanych czasach lutowania.

Mikrostrukturę połączeń lutowanych ujawniono przez trawienie chemiczne próbek odczynnikiem Buehlera. Badania metalograficzne przeprowadzono techniką w polu jasnym przy użyciu mikroskopu świetlnego MeF4M firmy Leica.

Badania metalograficzne połączeń lutowanych tytanu grade 2 przy użyciu folii miedzianej jako przekładki lutowniczej wykazały, że w strukturze połączenia lutowanego (po $1 \mathrm{~min}$ ) wyraźnie widać nieprzereagowaną warstwę lutu $z$ widoczną granicą lutowina-materiał podstawowy i szeroką strefą dyfuzyjną w materiale podstawowym o wyraźnie ciemniejszym zabarwieniu. W połączeniach wykonanych w czasie lutowania 10 i 20 min zaobserwowano wyraźne pęknięcia przebiegające na granicy lutowina - materiał podstawowy lub granicy pomiędzy obszarami faz występujących w lutowinie i wyraźnie różniących się zabarwieniem. W przypadku połączenia wykonanego w czasie lutowania 30 min prawie cały lut uległ przedyfundowaniu do materiału podstawowego, a w środkowej części złącza tylko lokalnie można był zaobserwować nieliczne obszary fazy o zabarwieniu wskazującym

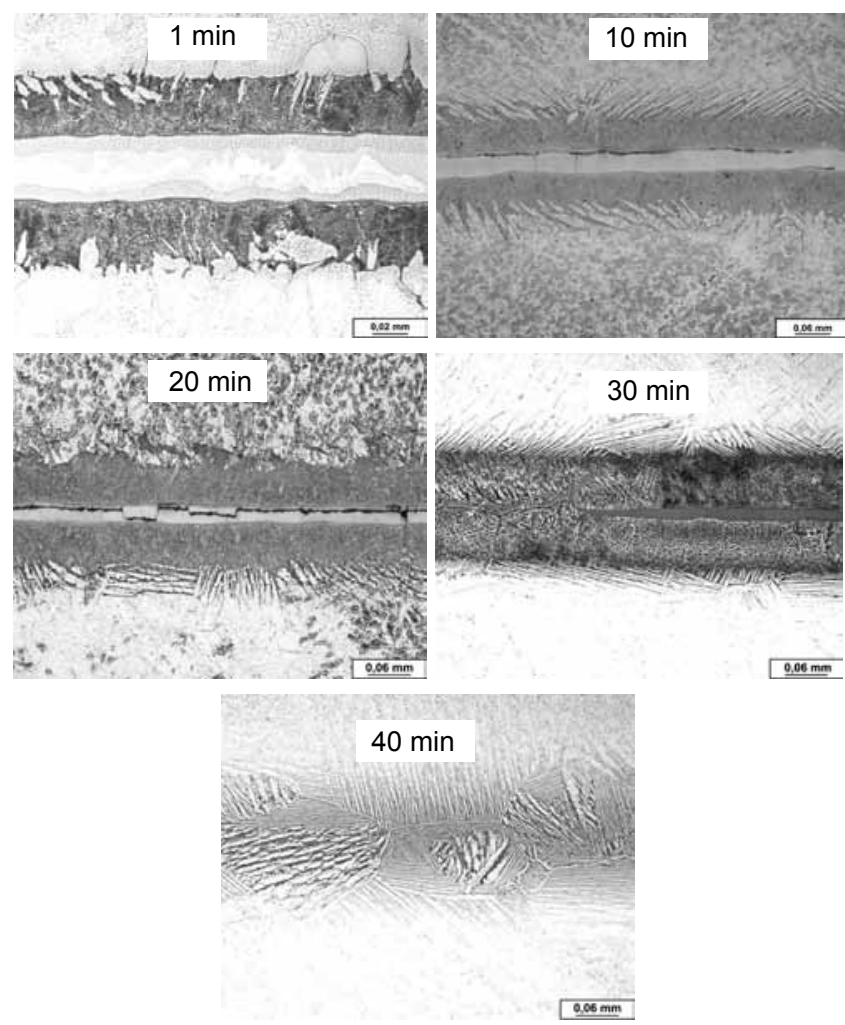

Rys. 2. Mikrostruktury połączeń tytanu (grade 2) lutowanych dyfuzyjnie z przekładką z miedzi, temperatura lutowania $1000{ }^{\circ} \mathrm{C}$, trawiono chemicznie odczynnikiem Buehlera

Fig. 2. Microstructures of titanium (grade 2) joints diffusion brazed using interlayer of $\mathrm{Cu}$ filler metal at $1000^{\circ} \mathrm{C}$, etched with Buehler etchant

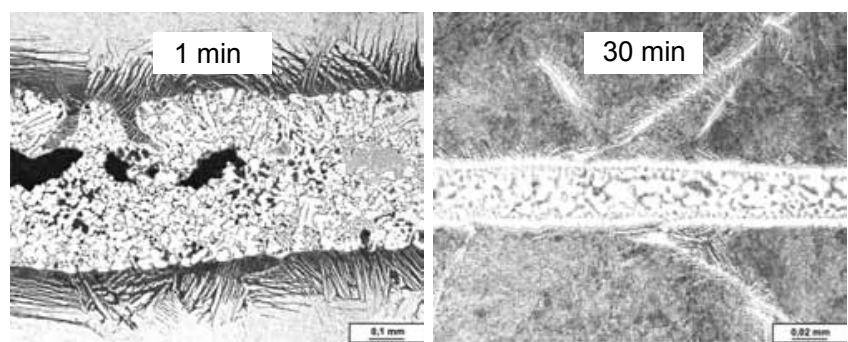

Rys. 3. Mikrostruktury połączeń tytanu (grade 2) lutowanych dyfuzyjnie z przekładką z niklu, temperatura lutowania $1000^{\circ} \mathrm{C}$, traw. chemicznie odczynnikiem Buehlera

Fig. 3. Microstructures of titanium (grade 2) joints diffusion brazed using interlayer of Ni filler metal at $1000^{\circ} \mathrm{C}$, etched with Buehler etchant

na duży udział miedzi. Zwiększenie czasu lutowania do 40 min spowodowało już całkowite przereagowanie materiału lutu i utworzenie gruboziarnistej struktury z iglastymi wydzieleniami wewnątrz ziaren. Struktury połączeń wykonanych przy użyciu miedzi przedstawiono na rysunku 2. Struktury lutowin połączeń tytanu wykonanych z użyciem lutu niklowego w temperaturze $1000^{\circ} \mathrm{C}$ i przy czasie wytrzymania 1 i 30 min charakteryzowały się częścią środkową o strukturze eutektycznej (stopiwo lutownicze) i wyraźnymi, poszerzającymi się wraz z wydłużeniem czasu lutowania, strefami dyfuzyjnymi z wydzieleniami iglastymi. Ponadto przy krótkim czasie lutowania (1 min) w środkowej strefie lutowiny zaobserwowano liczne pustki mogące świadczyć o występowaniu zjawiska Kirkendalla, polegającego na zróżnicowanej szybkości dyfuzji poszczególnych składników lutu i materiału podstawowego. Może to prowadzić do powstawania wakansów w obszarze materiału o niższej temperaturze topnienia (lutowiny) i większej szybkości dyfuzji atomów, które mogą się łączyć w defekty objętościowe, $\mathrm{np}$. w pory. Struktury połączeń lutowanych wykonanych przy użyciu niklu przedstawiono na rysunku 3.

\section{Statyczna próba ścinania tytanowych połączeń lutowanych}

Próby wytrzymałościowe lutowanych próbek o postaci walcowej przeprowadzono na maszynie wytrzymałościowej Instron 4210. Próbki mocowano w specjalnych uchwytach zaprojektowanych tak, aby połączenia poddane były jedynie siłom ścinającym, bez występowania naprężeń zginających. Największą wytrzymałość na ścinanie uzyskały połączenia wykonane w czasie lutowania 1 min dla obu zastosowanych lutów i 30 min dla połączeń uzyskanych przy użyciu przekładki miedzianej. Wytrzymałość połączeń lutowanych miedzią w czasie lutowania 10, 20 i 40 min w przypadku każdej stosowanej temperatury była mniejsza niż połączeń wykonywanych w czasie 1 i 30 min.

Wyniki statycznej próby ścinania próbek tytanowych lutowanych spoiwami $\mathrm{Cu}$ i $\mathrm{Ni}$ w różnym czasie 


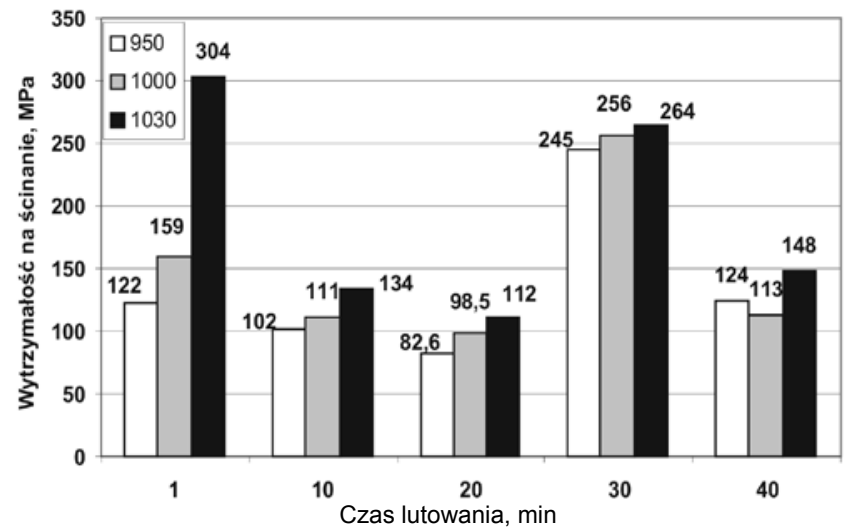

Rys. 4. Wytrzymałość na ścinanie połączeń lutowanych tytanu grade 2 wykonanych przy użyciu folii $\mathrm{Cu}$

Fig. 4. Shear strength of titanium grade 2 brazed using pure $\mathrm{Cu}$ filler metal

i różnej temperaturze lutowania przedstawiono odpowiednio na rysunkach 4 i 5 .

Badania wykazały, że największą wytrzymałością na ścinanie złączy lutowanych, wynoszącą $304 \mathrm{MPa}$ (średnia z pięciu prób), charakteryzują się połączenia wykonane przy użyciu miedzi w temperaturze $1030^{\circ} \mathrm{C} \mathrm{i}$ czasie lutowania $1 \mathrm{~min}$. Wysokie wartości wytrzymałości uzyskano również dla połączeń wykonanych w czasie 30 min. Ich wytrzymałość na ścinanie dla temperatury lutowania 950, 1000 i $1030^{\circ} \mathrm{C}$ wynosiła odpowiednio 245,256 i $264 \mathrm{MPa}$. Najmniejszą wytrzymałość połączeń lutowanych

\section{Wnioski}

Badania wykazały możliwość zastosowania czystej miedzi i niklu jako spoiw do lutowania dyfuzyjnego tytanu i uzyskania połączeń o fizycznej ciągłości i dobrej jakości.

Zastosowanie czystej miedzi umożliwia otrzymanie połączeń o wysokiej wytrzymałości na ścinanie, powyżej $260 \mathrm{MPa}$, wykonanych w temperaturze lutowania $1030^{\circ} \mathrm{C}$ oraz czasie 1 i $30 \mathrm{~min}$.

Niewłaściwie dobrane parametry lutowania tytanu przy użyciu przekładki miedzianej powodują

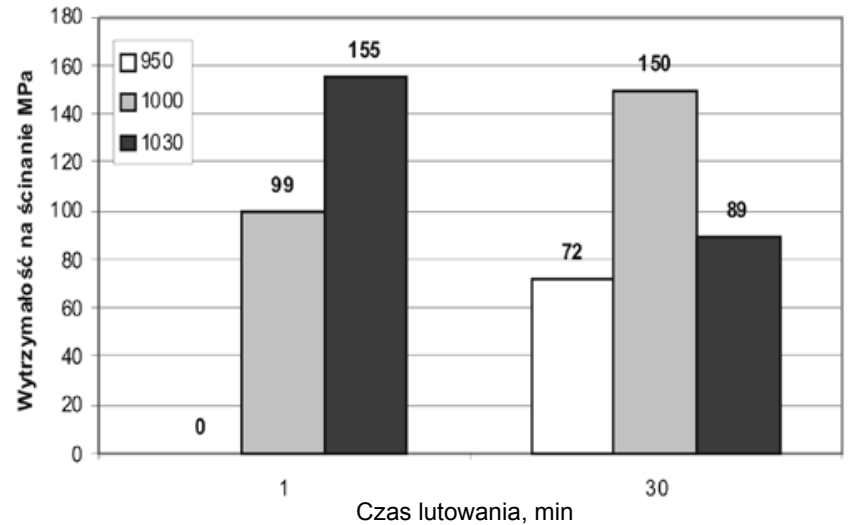

Rys. 5. Wytrzymałość na ścinanie połączeń lutowanych tytanu grade 2 wykonanych przy użyciu folii $\mathrm{Ni}$

Fig. 5. Shear strength of titanium grade 2 using of pure Ni filler metal

miedzią uzyskano dla czasów lutowania 10, 20 oraz 40 min.

Zdecydowanie mniejszą wytrzymałość na ścinanie mają połączenia lutowane przy użyciu niklu. Największą wartość osiągnięto dla czasu lutowania $1 \mathrm{~min}$ w temperaturze $1030^{\circ} \mathrm{C}$. Osiągnięcie dużej wytrzymałości złączy lutowanych w najwyższej temperaturze lutowania przy zastosowaniu którejkolwiek przekładki lutowniczej spowodowane jest prawdopodobnie przyspieszonymi procesami dyfuzyjnymi, a w przypadku miedzi jej zwiększoną rozpuszczalnością w fazie $\beta$ tytanu, występującej w całej objętości próbki.

\section{Literatura}

[1] Dobrzański L.A.: Podstawy nauki o materiałach i metaloznawstwo. WNT, Warszawa 2002.

[2] Szkliniarz W.: Stopy na osnowie faz międzymetalicznych z układu Ti-Al. Wydawnictwo Politechniki Śląskiej, Gliwice 2007.

[3] Schwartz M.: Brazing. Wyd. 2, ASM International, Materials Park, Ohio 2003.

[4] Praca zbiorowa: Brazing Handbook. AWS, Miami 2007.

[5] Lütjering G., Williams J.: Titanium, Springer-Verlag, Heidelberg 2003.

[6] Pilarczyk J.: Poradnik Inżyniera, Spawalnictwo. T. 1 i 2 , WNT, Warszawa 2003/2005.

[7] Praca zbiorowa: Principles of brazing. Diffusion brazing ASM International, 2005.

powstawanie w złączu lutowanym licznych pęknięć lub pojawienie się w środkowej strefie lutowiny granicy frontów krystalizacji. Prowadzi to do znacznego zmniejszenia wytrzymałości na ścinanie połączeń lutowanych do wartości poniżej $100 \mathrm{MPa}$.

Wytrzymałość na ścinanie połączeń lutowanych przy użyciu niklu nie przekracza $155 \mathrm{MPa}$, co wynika $z$ obecności licznych pustek w obszarze lutowiny.

[8] Gale W.F.: Applying TLP bonding to the joining of structural intermetallic compounds. Journal of Metals, nr 2/1999, s. $49-52$.

[9] Mirski Z., Różański M.: Lutowanie dyfuzyjne tytanu i jego stopu na osnowie fazy TiAl (y). Inżynieria Materiałowa, nr 2/2010, s. 161-166.

[10] Winiowski A., Różański M.: Badanie procesów lutowania dyfuzyjnego tytanu i jego stopów. Praca badawcza IS nr Cc50.2/ST-247.2, 2007.

[11] Wojewoda J., Zięba P.: Lutowanie dyfuzyjne niskotemperaturowe. Część I: Aspekty strukturalne. Inżynieria Materiałowa, nr 1/2004, s. 11-23.

[12] Massalski T.B.: Binary alloy phase diagrams. American Society for Metals, Ohio 1987. 